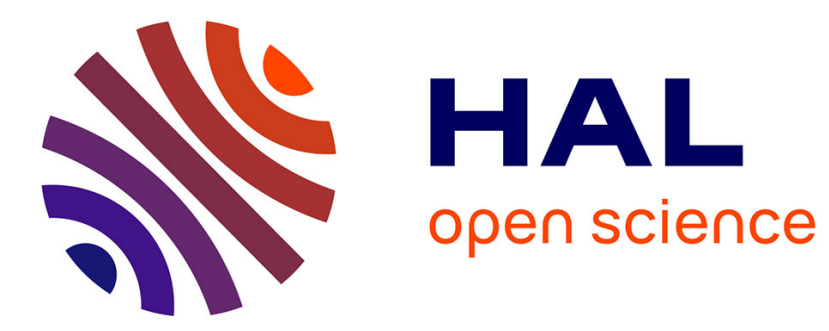

\title{
Use of Flight Simulators in Analyzing Pilot Behavior
}

Jan Boril, Miroslav Jirgl, Rudolf Jalovecky

\section{To cite this version:}

Jan Boril, Miroslav Jirgl, Rudolf Jalovecky. Use of Flight Simulators in Analyzing Pilot Behavior. 12th IFIP International Conference on Artificial Intelligence Applications and Innovations (AIAI), Sep 2016, Thessaloniki, Greece. pp.255-263, 10.1007/978-3-319-44944-9_22 . hal-01557635

\section{HAL Id: hal-01557635 \\ https://hal.inria.fr/hal-01557635}

Submitted on 6 Jul 2017

HAL is a multi-disciplinary open access archive for the deposit and dissemination of scientific research documents, whether they are published or not. The documents may come from teaching and research institutions in France or abroad, or from public or private research centers.
L'archive ouverte pluridisciplinaire HAL, est destinée au dépôt et à la diffusion de documents scientifiques de niveau recherche, publiés ou non, émanant des établissements d'enseignement et de recherche français ou étrangers, des laboratoires publics ou privés. 


\title{
Use of Flight Simulators in Analyzing Pilot Behavior
}

\author{
Jan Boril ${ }^{1}$, Miroslav Jirgl ${ }^{2}$, and Rudolf Jalovecky ${ }^{1}$ \\ ${ }^{1}$ University of Defence, Brno, Czech Republic \\ \{jan.boril, rudolf.jalovecky\}@unob.cz \\ ${ }^{2}$ Brno University of Technology, Brno, Czech Republic \\ miroslav.jirglephd.feec.vutbr.cz
}

\begin{abstract}
This paper describes simulation technologies in their current state as they are in the general aviation and at the University of Defence. The authors present a methodology of measurement, evaluation and modelling of pilots' behavior, both before and after flight training (20 hours) on real airplanes. By means of transfer function equation of human behavior model and time constants resulting from them, the authors analyze their change depending on the continuing training of students - pilots of military aircraft. Based on the results of these analyses, they have found a positive trend in the development of pilots' transport delay and their abilities to adapt themselves to flight dynamics of an airplane.
\end{abstract}

Keywords: Flight Simulators · Pilot Training · Human Behavior Model · Time Constants $\cdot$ MATLAB ${ }^{\circledR} \cdot$ X-Plane

\section{Introduction}

In modern aviation flight simulations play an irreplaceable role both in pilot training and maintaining their needed habits. The level of safety in transport as well as individual aviation now considerably depends on simulation technologies that are used not only for training but also for investigation of aircraft accidents, studying airplane designs, or better understanding of ergonomic relations [1]. The importance of flight simulators is increasing proportionally with growing complexity of modern aviation systems, so training on simulators has become an inseparable part of pilot training, their professional growth and research focused on adaptability of aircraft environment to human capabilities and limits. As a result of the constant development of pilot natural working environment, flight simulators are becoming an invaluable instrument.

Indispensable part of training is currently being transferred from flight training on planes to simulators for the reasons of undisputable advantages that this type of training offers. The growing significance of flight simulations is also evidenced in the latest international regulations stipulating requirements for aviation synthetic training equipment. Training efficiency can be achieved with use of synthetic equipment of a low reliability for some types of missions. Thanks to the interconnection of flight simulations with the rapidly growing field of computer technologies, the synthetic 
methods offer more and more opportunities in running effective training of flying crews and maintenance personnel [2].

As a result of progress made in the field of avionics, the complexity of civilian and military airplanes have increased too, which puts higher demands on crew training and strengthens the dependency on flight simulations. For the reasons of crew training and retaining their licenses many civilian airlines have established and are running large aviation training centers. Not only have flight simulation radically changed flight training methods in terms of reducing risks and increasing quality of training, but they have also resulted in a significantly higher flight safety, decreased traffic density, and positive effect on environment, when all of that is achieved in reducing cost of flight training. These trends will continue in the foreseeable future $[2,3]$.

The main goal of this paper is to verify the potentiality of using flight simulators and subsequent application of mathematical methods to evaluation of pilot training experience. Currently, the authors are in the phase of repeated measurements running under the equal conditions and with the same pilots. The aim of which is to verify the accuracy of all analyses depending on repeatability with an emphasis laid on changes resulting from continuous training.

\section{Mathematical Equation of Human Behavior}

The literature offers us several works dealing with modelling of human behavior, including pilots. Most of these papers are based on the description (1) first presented by D.T.McRuer in the 1970s which models human behavior primarily at the level of the feedback regulator as described above. It is a linear model (transfer function) of a proportionally-derivative regulator with a second order lag and time (reaction) delay, in which each of the constants has a certain physiological or neurological interpretation $[4,5,6]$ :

$$
F(s)=\frac{Y(s)}{X(s)}=K \frac{\left(T_{3} s+1\right)}{\left(T_{1} s+1\right)\left(T_{2} s+1\right)} e^{-\tau s} .
$$

Where

$\mathrm{K} \quad$ Pilot gain representing a pilot's habits in response to a certain action. It is also connected with the input and output signal ratio.

$\mathrm{T}_{1} \quad$ Neuromuscular lag time constant expressing a pilot's delayed reaction resulting from his neuromuscular system. It ranges from 0.05 to $0.2 \mathrm{~s}$ and is not dependent on the training intensity.

$\mathrm{T}_{2} \quad$ Lag time constant characterizing a pilot's promptness and agility. Thus it is related to performing acquired stereotypes and routine procedures. Ranges from $0.1 \mathrm{~s}$ to $5 \mathrm{~s}$.

$\mathrm{T}_{3} \quad$ Lead time constant connected with a pilot's experience. It reflects a pilot's capability to predict a situation that may occur. This capability is developed through training and experience and ranges from $0.2 \mathrm{~s}$ to $15 \mathrm{~s}$.

$\tau \quad$ Time constant expressing a delayed reaction in pilot's brain to a motional 
and visual perception. As a result of fatigue this constant can be extended and the pilot's regulating capabilities may subsequently fail, thus the regulating system becomes unstable. This constant most frequently ranges from 0.3 to $1 \mathrm{~s}$.

The model in the form of equation (1) is a general model that may be used in a wide spectrum of activities connected with driving [7] or piloting. Individual constants most frequently reach the values within the ranges as shown above, and depend on pilots' abilities to adapt to the controlled dynamics (adaptability).

Validity of this model was verified on the basis of many experiments, and primarily thanks to its simplicity it turned out to be a very efficient tool for description and modelling of a pilot's reactions [6], [8].

The identification algorithm as written in MATLAB environment is used to identify model parameters. This algorithm is based on applying the library function fminsearch resulting from Nelder-Mead simplex algorithm [9]. The criterial function for searching for parameter is then in the form of the sum of squared deviations, see equation (2):

$$
K R I T=\sum_{i=1}^{n}\left(y(i)-y_{m}(i)\right)^{2}
$$

Where

y real (measured) value of the output quantity (pilot's intervention),

$\mathrm{y}_{\mathrm{m}}$ modelled (estimated) value of the output quantity (pilot's intervention),

$\mathrm{n}$ length of data.

The Best fit [\%] parameter is used for expressing the accuracy of identification because it gives an opportunity for making an easy comparison of identification results with those obtained through MATLAB - System Identification Toolbox. The equation for calculating the Best fit parameter is as follows [10]:

$$
f i t=100\left(1-\frac{\left\|y-y_{m}\right\|}{\|y-\operatorname{mean}(y)\|}\right) .
$$

Where

y real (measured) value of the output quantity (pilot's intervention),

$\mathrm{y}_{\mathrm{m}}$ modelled (estimated) value of the output quantity (pilot's intervention).

\section{Description of Experimental Workplace and Measurement Procedure}

Most of armed forces also use training centers equipped with flight simulators designed for basic training, transitions to another type of aircraft, and tactical training on 
the platform of both fixed-wing and rotary-wing aircraft. Beyond doubt simulations provide a wide range of true advantages, therefore a growing number of synthetic equipment is being introduced into modern air forces to be used in a broad spectrum of activities, mainly for training of aviation personnel [11]. In addition, flight simulators are used by aircraft and airplane equipment manufacturers, system developers, research organizations and academies whose effort is aimed at proving the validity of studies, designs, developments and calculations of flight systems.

\subsection{Flight Simulator at the University of Defence}

The Department of Air Electrical Systems strives to keep up with these above mention trends, therefore the flight simulator based on X-Plane-10 software was built up to raise the quality of training and create a capacity for scientific research. The mission of the flight simulator at the University of Defence does not lie in competing with or replicating modern sophisticated simulators designed for pilot basic or improvement training. Using this simulator the authors prepare their procedures and methods for data gathering and evaluation. Currently, as described in the chapter Introduction, the authors are in the phase of repeated measurements running under the equal conditions and with the same pilots. The aim of which is to verify the accuracy of all analyses depending on repeatability with an emphasis laid on changes resulting from continuous training. Based on the knowledge obtained in such a manner, they will be able to implement the methodology of measurement and data evaluation on commercial full flight simulators.

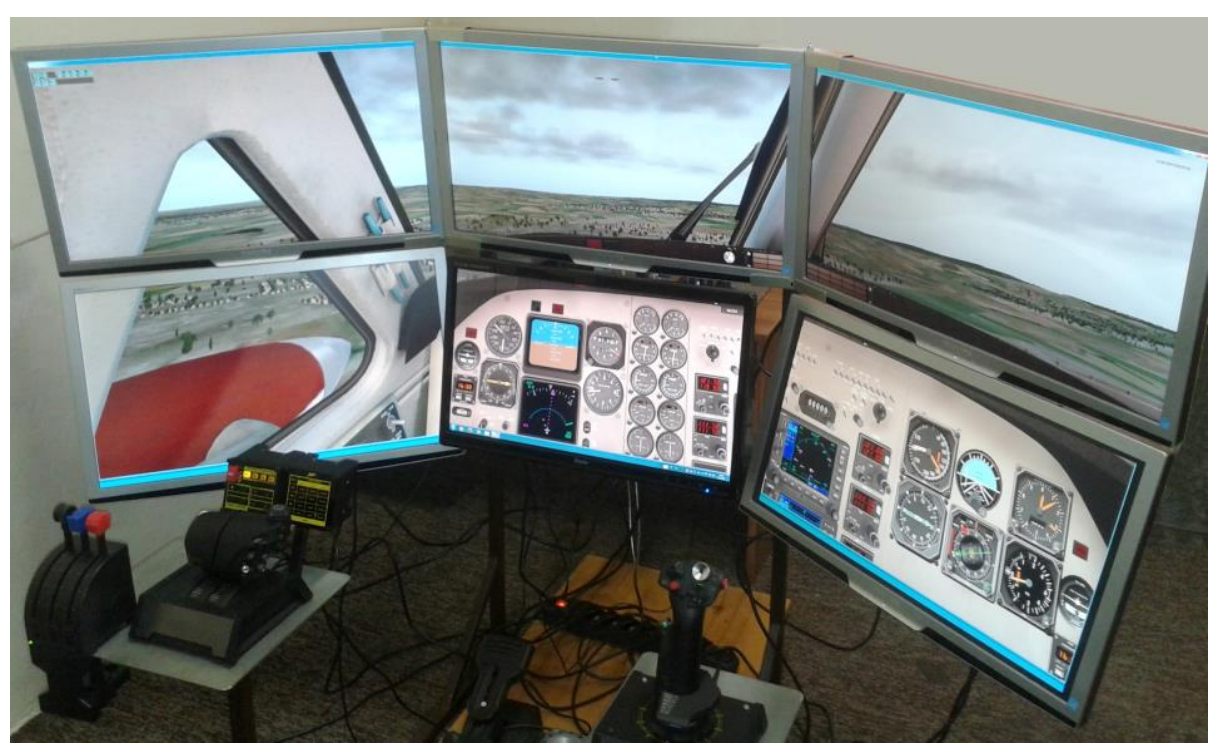

Fig.1. The simulator at the Department of Air Electrical Systems, University of Defence, built on the basis of X-Plane 10 simulation program. 
Throughout the whole world this simulator program is currently rated as a comprehensive, complex and highly efficient PC flight simulator that offers most advanced flight models and tools. This engineering tool has been designed for an easy estimate of a flight model of all categories of aircraft and their construction types. The information acquired from mathematical and physical calculations in real time are relatively precise. The basic version of X-Plane software offers dynamics of 30 airplanes, such as Bell 206 JetRanger helicopter, Cessna 172, King-Air C90 etc. From the previous experience the King-Air C90 airplane (Fig. 1) was chosen for testing a pilot's response to an unexpected flight situation. The simulator is capable to record the flight trajectory (selected parameters) and safe them into a text file in $20 \mathrm{~Hz}$ frequency.

\subsection{Experimental Flight Task}

A flight mode was defined - altitude of $2900 \mathrm{ft}$, speed $170 \mathrm{mph}$, angle of attack and pitch angle, including their change, was approximately zero (note $1 \mathrm{ft}=0.305 \mathrm{~m}$ and $1 \mathrm{mph}=0.447 \mathrm{~m} \cdot \mathrm{s}^{-1}$ ). At a certain time the altitude was step-changed to $2600 \mathrm{ft}$ and the task of the pilot was to correct the altitude back to the original flight level $2900 \mathrm{ft}$. A total of 6 trainee pilots were tested in this flight mode, all of them had about 60-80 flight hours of experience in the Zlin Z-142C AF aircraft. Each pilot had the altitude changed 10 times one after another, always after putting the aircraft back into the initial flight state.

The whole experiment was repeated after 6 months. The tested subjects were the same pilots. These pilots were trained within this time and the experience was increased by about 20 hours.

\section{Measurement and Data Analysis}

For the purpose of demonstrating the results, an analysis of pilot no. 1 was made, as shown below. The evaluation of other flights was carried out in a similar manner.

Fig. 2 presents data measured on the simulator by pilot's no. 1 containing individual measurements performed a) in spring 2015, b) in fall 2015 (after the training). On the left side are always altitude records by airplane $H$ depending on the stick deflection (pilot's reaction) $d v$, as shown on the right side. The red curve indicates the arithmetic average of individual measurements, i.e. average pilot's response and flight altitude reached by the plane calculated out of 10 measurements.

In order to evaluate the level of pilot training, i.e. compare changes in their responses, it is advisable to create and define the so-called average pilot behavior model. The parameters of an average pilot behavior model as described by the equation (1) were identified from the average responses - red curves in Fig. 2 using the identification algorithm, as described above. 

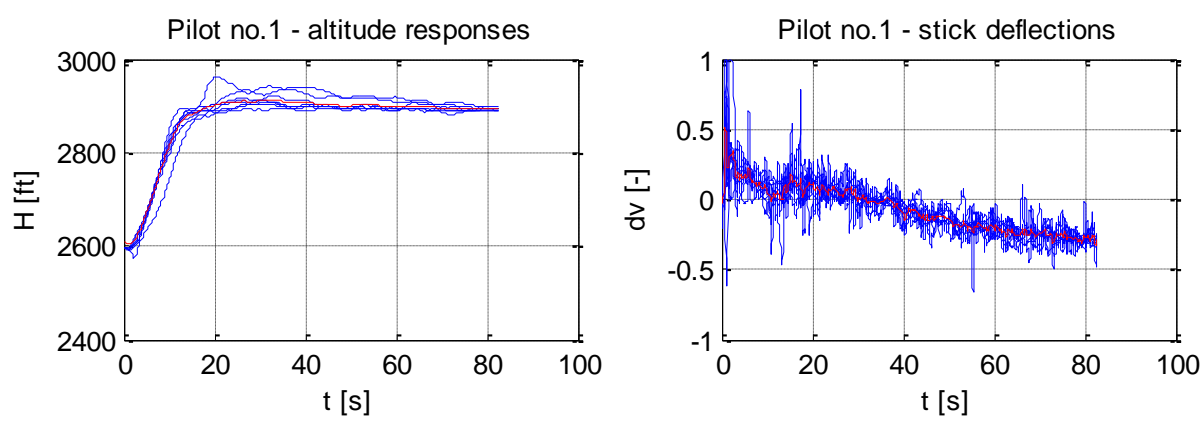

a)
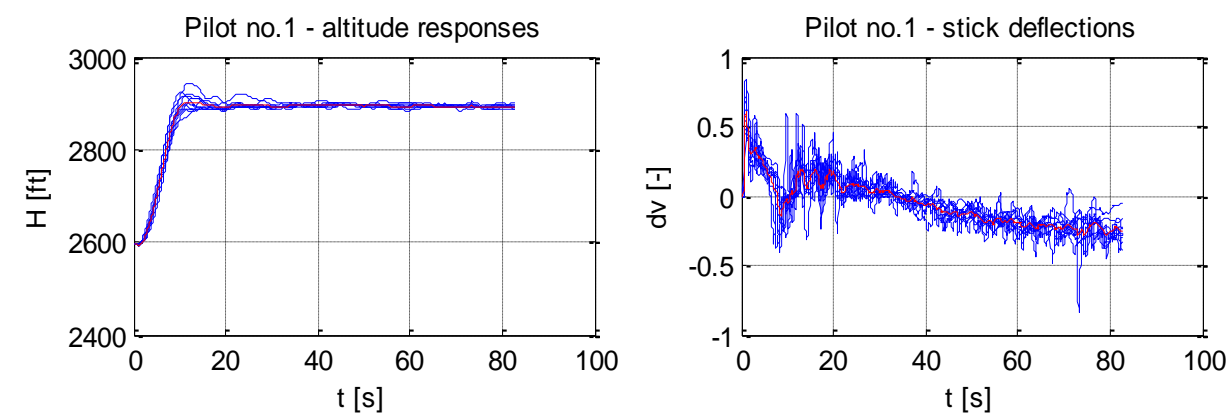

b)

Fig. 2. Simulator measured data - pilot no.1: a) measured in spring 2015, b) fall 2015.

Thus, the identification results in the average pilot behavior model in the following form:

- spring 2015

$$
F_{1 A}(s)=6.84 \cdot 10^{-4} \frac{(1.62 s+1)}{(0.13 s+1)(0.46 s+1)} \cdot \exp (-0.7 s)
$$

Best fit $=47.43 \%$

- fall 2015

$$
F_{1 B}(s)=8.02 \cdot 10^{-4} \frac{(2.21 s+1)}{(0.13 s+1)(0.80 s+1)} \cdot \exp (-0.62 s)
$$

Best fit $=45.62 \%$

The approximation of the original responses (measured data) with use of the responses of identified models $F_{1 \mathrm{~A}}(s)$ and $F_{1 \mathrm{~B}}(s)$ is shown in Fig. 3. 


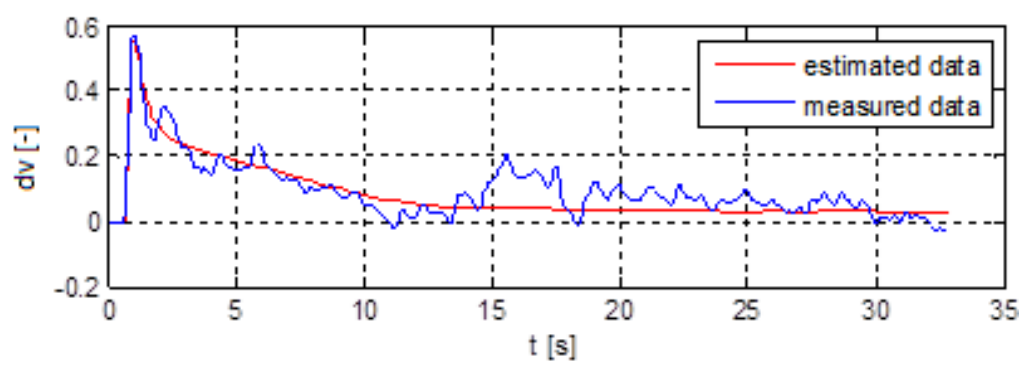

a)

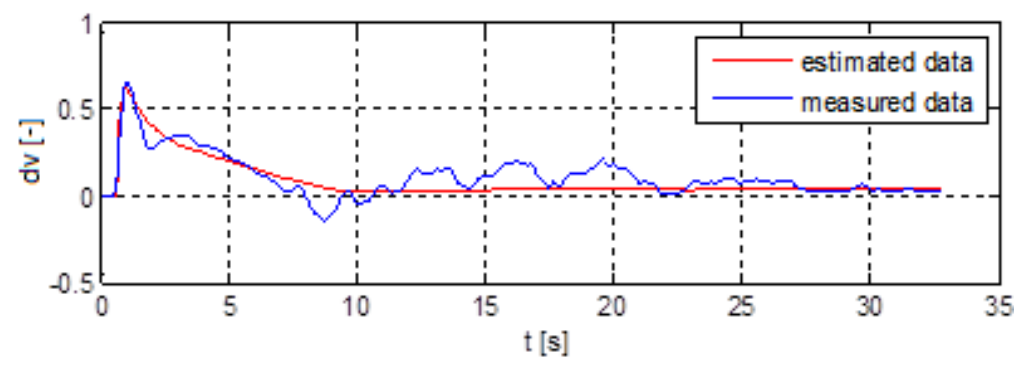

b)

Fig. 3. The result achieved from parameter identification of pilot behavior model (pilot no.1) : a) measured in 2015, b) fall 2015 .

Apparently the results indicate that practically all parameters of the model were changed. Both lead time constant $T_{3}$ and lag time constant $T_{2}$, being in relation with pilot's experience and length of flying practice, increased. On the contrary, the value of transport delay $\tau$ dropped, which means that average pilot reaction is faster by almost $0.1 \mathrm{~s}$. Neuromuscular lag time constant $T_{1}$ remained unchanged. This constant represents dynamics of spreading impulses throughout human neuromuscular system. Its numeric value, i.e. approximately $0.13 \mathrm{~s}$, also conforms to the theory.

The testing measurements and data analysis were carried out similarly with other pilots. The below-stated table summarizes the results achieved from the parameter identification of pilot behavior model [12,13]. Letter A stands for the measurement taking place in spring 2015, whereas B for the measurement in fall 2015.

Table 1. Parameters of the identified transfer functions for pilots $1-6$.

\begin{tabular}{lcccccccccc}
\hline & $\mathrm{A}$ & $\mathrm{B}$ & $\mathrm{A}$ & $\mathrm{B}$ & $\mathrm{A}$ & $\mathrm{B}$ & $\mathrm{A}$ & $\mathrm{B}$ & $\mathrm{A}$ & $\mathrm{B}$ \\
& $\mathrm{K} .10^{-4}[-]$ & $\mathrm{K} .10^{-4}[-]$ & $\mathrm{T}_{1}[\mathrm{~s}]$ & $\mathrm{T}_{1}[\mathrm{~s}]$ & $\mathrm{T}_{2}[\mathrm{~s}]$ & $\mathrm{T}_{2}[\mathrm{~s}]$ & $\mathrm{T}_{3}[\mathrm{~s}]$ & $\mathrm{T}_{3}[\mathrm{~s}]$ & $\tau[\mathrm{s}]$ & $\tau[\mathrm{s}]$ \\
\hline Pilot no.1 & 6.84 & 8.02 & 0.13 & 0.13 & 0.46 & 0.80 & 1.62 & 2.21 & 0.70 & 0.62 \\
Pilot no.2 & 6.33 & 7.39 & 0.13 & 0.14 & 1.15 & 1.51 & 3.16 & 5.22 & 0.78 & 0.73 \\
Pilot no.3 & 8.61 & 5.41 & 0.07 & 0.07 & 0.98 & 1.11 & 2.81 & 2.32 & 0.68 & 0.87 \\
Pilot no.4 & 5.67 & 6.99 & 0.17 & 0.17 & 1.44 & 1.29 & 2.69 & 2.50 & 0.85 & 0.84 \\
Pilot no.5 & 7.43 & 7.44 & 0.12 & 0.11 & 1.14 & 1.12 & 2.44 & 3.41 & 0.76 & 0.72 \\
Pilot no.6 & 8.06 & 7.39 & 0.08 & 0.07 & 1.25 & 1.49 & 3.41 & 2.96 & 0.82 & 0.72 \\
\hline
\end{tabular}


The results as shown in Table 1 clearly indicate that the values of neuromuscular lag time constant $T_{1}$ remain in repeated measurements practically unchanged, which confirms the premise that their value is independent of the training intensity and is characteristic for all pilots. All pilots, except for pilot no. 3, display decreased value in response time (transport delay) $\tau$, which means that pilots are able to response to a changed situation faster. The ratio between regulating constants $T_{2}$ and $T_{3}$ determines adaptability to controlled dynamics. Changes were mostly recorded even in this case.

\section{Conclusion}

The aim of this paper was to verify the potentiality of using flight simulators and subsequent application of mathematical methods in order to carry out an objective assessment of pilot training experience in terms of intensity and status. Two sets of measurements focused on pilots' response (reaction) to a visual stimulus with use of a stationary flight simulator were simultaneously performed at the University of Defence in Brno.

Both measurements were always running under identical conditions, i.e. with pilots who had flown around $60-80$ hours in real airplane before the first measurement. Another measurement took place after six months when pilots completed another training phase and their recorded number of flying hours increased approximately by 20 hours.

Based on the measured data the authors made mathematical analyses needed to generate models of pilot behavior. On the grounds of these models authors were then able to create the so-called average pilot behavior model. Having compared the average pilot behavior model for individual measurements (before and after training), the authors, in most cases, registered a change, which specifically means that pilots' transport delay and the ratio between regulating constants, featuring the pilots' adaptability to controlled dynamics, changed too. The achieved results outline a potentiality of a further development in this field in the future. Hence more sets of measurement are needed to be performed in a foreseeable time horizon to verify the applied methodology.

Acknowledgments. The paper was written within project Technology Agency of the Czech Republic n.TA04031376 research / development methodology training aviation specialists L410UVP E20 and grant No. FEKT-S-14-2429 - "The research of new control methods, measurement procedures and intelligent instruments in automation", and the related financial assistance was provided from the internal science fund of Brno University of Technology.

\section{References}

1. Boril, J., Leuchter, J., Smrz, V., Blash, E.: Aviation Simulation Training in the Czech AirForce. In: 34th Digital Avionics Systems Conference, pp. "9A2-1" - "9A2-13". ALR International, Florida, Orlando (2015)

2. Allerton, D.: The impact of flight simulation in aerospace. Aeronautical Journal, 747-756 (2010) 
3. Foyle, D.C., Hooey, B.L.: Human Performance Modeling in Aviation. CRC Press. Boca Raton; New York; London (2008)

4. McRuer, D.T., Krendel, E.S.: Mathematical Models of Human Pilot Behavior. System Technology, INC. AGARD AG 188, Paper No. 146, Hawthorne California, (1974)

5. Lone, M. M., Cooke, A. K.: Development of a Pilot Model Suitable for the Simulation of Large Aircraft. In: 27th International Congress of Aeronautical Sciences, Paper ICAS 2010-6.7.2. (2010)

6. Hess R. A., Marchesi F.: Analytical Assessment of Flight Simulator Fidelity Using Pilot Models. Journal of Guidance, Control and Dynamics, Vol. 32, 760-770 (2009)

7. Havlikova, M.: Diagnostic of Systems with a Human Operator, Doctoral Thesis (in Czech). Brno University of Technology (2008)

8. Glodek M., Honold F., Geier T., Krell G., Nothdurft F., ReuterS., et al.: Fusion Paradigms in Cognitive Technical Systems for Human-Computer Interaction. Neurocomputing, Vol. 161, 17-37 (2015)

9. Lagarias, J.C., Reeds, J. A., Wright, H., Wright, P. E.: Convergence Properties of the Nelder-Mead Simplex Method in Low Dimensions. SIAM J. Optim., vol. 9, no. 1, 112117 (1998)

10. Ljung, L.: Experiments with Identification of Continuous Time Models. In 15th IFAC Symposium on System Identification, pp. 1175-1180 (2009)

11. Allerton, D.: Principles of Flight Simulation. John Wiley \& Sons, Ltd. (2009)

12. Boril, J., Jalovecky, R.: Mathematical Analysis of Human Factors Using Experimental Parameter Identification of Human Behaviour Model. Engineering Intelligent Systems, vol. 21, no. 2, 1-11 (2013)

13. Boril, J., Jalovecky, R.: Experimental Identification of Pilot Response Using Measured Data from a Flight Simulator. In: Artificial Intelligence Applications and Innovations. pp. 126-135.Springer, Heidelberg (2012) 